\title{
Atenco, a diez años del movimiento social por el proyecto del aeropuerto. Análisis sociourbano y político
}

\author{
Enrique Moreno Sánchez*
}

En el presente trabajo se presenta una reflexión acerca del movimiento social que surgió hace más de un decenio en el municipio de Atenco, Estado de México, que generó una serie de manifestaciones campesinas, obreras y populares de apropiación y defensa de la tierra en un territorio que forma parte de la Zona Metropolitana de la Ciudad de México (ZMCM). El movimiento - definido desde un principio como contrario a la propuesta del proyecto de construcción del aeropuerto internacional-no es un asunto concluido, pues ha generado una nueva forma de organización social en dicho municipio. Después de un decenio la configuración sociourbana y politica de Atenco ha cambiado y hoy se presenta como un territorio con características insertas en la dinámica urbana, con un nuevo perfil social y político.

Palabras clave: Atenco, movimiento social, aeropuerto, análisis sociourbano y político.

Fecha de recepción: 8 de agosto de 2012.

Fecha de aceptación: 21 de octubre de 2013.

\section{Atenco, Ten Years after the Social Movement in Response to the Airport Project. Socio-Urban and Political Analysis}

This work focuses on the social movement that emerged over a decade ago in the town of Atenco in the State of Mexico, which triggered a series of farmers', workers' and popular demonstrations to appropriate and defend the land, which belongs to the Metropolitan Zone of Mexico City (ZMCM). The movement, defined from the beginning as opposing the proposal to build the international airport, is not finished business, as it has given rise to a new form of social organization in Atenco. Ten years later, Atenco's socio-urban and political configuration has changed, and today it is a territory with the characteristics of the urban dynamic, and a new social and political profile.

Key words: Atenco, social movement, airport, socio-urban and political analysis.

* Profesor de la Unidad Académica Profesional Texcoco de la Universidad Autónoma del Estado de México (UAEM). Dirección postal: Km 8.5 Carretera Texcoco-Los Reyes La Paz, 56190, Texcoco, Estado de México, México. Correo electrónico: <enriquetex132 @gmail.com>.

$\overline{\text { ESTUDIOS DEMOGRÁFICOS Y URBANOS, VOL. 29, NÚM. } 3 \text { (87), 2014, 541-578 }}$ 


\section{Introducción}

El movimiento social que se desarrolló en el municipio de Atenco en el Estado de México se definió desde el inicio del año 2001 como contrario a la construcción del aeropuerto internacional de la Ciudad de México, un proyecto que fue considerado en su momento como propuesta a desarrollar en el territorio mexiquense. En este trabajo se reflexiona sobre la articulación de dicho movimiento con los cambios sociales, políticos y urbanos que surgieron en el periodo 2001-2011 y sobre su relación con la propuesta de una obra urbana tan importante para el país. Es de señalar que el movimiento social continúa vigente y el Frente de Pueblos en Defensa de la Tierra (FPDT) sigue en su lucha, con menor relevancia en el municipio pero mayor en otros espacios locales, vinculado con las distintas luchas sociales en el país y en el extranjero relacionadas con la tierra y con los derechos humanos, ambientales, ciudadanos y sociales -entre los más significativos-, y ha cumplido ya un decenio.

El trabajo analiza la transformación que experimentó Atenco en el último decenio (2001-2011) atendiendo a los aspectos social, urbano y sociopolítico. Los indicadores estadísticos muestran que en el periodo estudiado el sector terciario cambió la estructura de un tipo de desarrollo económico que en los años sesenta y setenta sustentaba gran parte de su economía en el sector primario. Lo anterior conduce a plantear las siguientes preguntas: ¿Se pueden hacer coincidir las variables sociopolíticas y las urbanas en el municipio de Atenco? ¿Existe una política de ordenamiento urbano-territorial y ambiental para ese municipio y para los que se ubican en la región Texcoco? ¿Es necesario un nuevo aeropuerto internacional en la ZMCM? ¿El FPDT representa a una sociedad que se vincula con lucha social necesaria contra un Estado opresor?

Este artículo responde dichas preguntas con trazos que son fundamentales para analizar y estudiar de mejor manera al municipio, la población y sus procesos sociales y urbanos, y contribuye a delinear el perfil de largo plazo del municipio, la región y el estado. El vínculo de esta región con la Zona Metropolitana de la Ciudad de México ${ }^{1}$

1 Según el INEgI en el año 2000 la Zona Metropolitana de la Ciudad de México comprendía la misma Ciudad de México y sus 16 delegaciones, más 27 municipios conurbados del Estado de México y el municipio de Tizayuca en el estado de Hidalgo, con una población estimada de 17 millones de habitantes en dicha región. Otra demarcación y división administrativa, la llamada Zona Metropolitana del Valle de México (ZMVM), 
(ZMCM) adquiere mayor significado porque implica la definición de umbrales de crecimiento económico y poblacional para una zona más grande y con mayor complejidad, dadas las características territoriales, sociales, económicas, políticas y urbanas del Distrito Federal, que alberga la Ciudad de México, y los municipios del Estado de México que, como Atenco, desarrollan actividades muy particulares, pero están insertos en la dinámica metropolitana de la ciudad más grande de Latinoamérica.

$\mathrm{Al}$ analizar el movimiento social de Atenco es indispensable referirse a los actores sociales con una perspectiva sociológica. Se trata de ejidatarios de una localidad cercana a la gran Ciudad de México que pertenecen a sectores populares en los que se da una transformación del actor-sujeto: a) Los actores de este movimiento se identifican y estructuran a partir de cierta identidad, demandas y principios, con las particularidades propias de la condición sociocultural de la categoría social a la que pertenecen; $b$ ) por sus mismas demandas o reivindicaciones respecto a su condición, y $c$ ) por las características organizacionales e institucionales del medio en que se desenvuelven (Munck, 1995).

Cristina Alcayaga (2002) considera que cada movimiento social está relacionado con el dato social mismo y con los procesos históricos culturales que entienden la democracia como igualdad social. Los movimientos sociales no sólo son ejecutores de proyectos vinculados con la democracia y la igualdad social, sino que además expresan una racionalidad. Sin embargo, Armando Cisneros (2002) considera que el análisis de los movimientos sociales parece requerir aún de una percepción crítica, donde se pueden abordar valores políticos y dar un valor a los movimientos sociales de cada momento histórico.

El objetivo de este trabajo es analizar los sucesos que desencadenó el movimiento social de Atenco en el decenio 2001 a 2011 y su gran difusión local, nacional e internacional; asimismo conocer los cambios urbanos, sociales y políticos que ha experimentado dicho territorio ubicado en la región oriente del Estado de México y sus vínculos con los nuevos escenarios políticos y urbanos de la región, del estado y del país.

es más amplia y abarca 59 municipios del Estado de México, 16 delegaciones del Distrito Federal, 29 municipios del Estado de México, y el municipio de Tizayuca del estado de Hidalgo, con lo cual se complica la región, ya que aloja a 21163226 pobladores, según especifica Sedesol / INEGI / Conapo en su documento Zona Metropolitana del Valle de México, que editaron el Gobierno del Estado de México y Coespo en el año 2009. 
Para la formulación de las conclusiones y el proceso de recopilación de información se realizaron entrevistas y estudios de campo con el apoyo de las comunidades de San Salvador Atenco, Acuexcomac, Santa Isabel Ixtapan, Nexquipáyac, todas pertenecientes al municipio de Atenco en el Estado de México. La primera fase se desarrolló de agosto a noviembre de 2011 y la segunda de febrero a marzo de 2012.

Este artículo se ha organizado en cuatro partes. En la primera se reflexiona acerca del movimiento social de Atenco; en la segunda se refieren las principales características territoriales sociourbanas y económicas del municipio en el periodo señalado. En la siguiente se describe el cambio político de Atenco y se destacan los cambios más significativos que sufrieron el gobierno local, el estatal y el federal en el periodo 2001 al 2011; en la cuarta parte se examina el papel del Frente de Pueblos en Defensa de la Tierra y su conformación en el movimiento social a partir del año 2001, y, finalmente, se presentan las conclusiones.

\section{El movimiento social de Atenco}

Con la exposición teórica y su relación con el caso analizado, en el presente trabajo se pretende contribuir a un mejor entendimiento de la literatura de los movimientos sociales en México, y en particular sobre el caso de Atenco, que muestra cómo un conflicto social puede llegar a generar un movimiento social y exhibir una realidad que se entrelaza con un modelo económico y/o cultural. También se apunta una acción de los nuevos movimientos sociales del siglo XxI que se desarrolla en el ámbito de lo local-regional, con efecto en el Estadonación.

Es necesario también analizar y reflexionar sobre la necesidad de ubicar un nuevo aeropuerto internacional en Atenco y Texcoco, territorios que pertenecen a la zona metropolitana más importante de Latinoamérica. También se ha de pensar si se requieren los grandes cambios de infraestructura urbana asociados a los megaproyectos urbanos y que en el presente son referentes de la competitividad internacional que tienen los distintos estados. Lo anterior no se puede explicar sin incluir la dimensión social, porque precisamente son los individuos quienes se ven afectados por una decisión de gobierno que acarrea otros referentes no considerados en la toma de decisiones. Cabe así preguntar: ¿es el FPDT una organización que expresa en gran 
medida los problemas del campo y la ciudad, de lo urbano, de las políticas públicas y gubernamentales de los distintos gobiernos? Esto lleva a la reflexión y al análisis en el estudio del tema que nos ocupa.

En este punto es relevante entender que no fue igual el grado de participación de los distintos actores del movimiento de Atenco. Los movimientos sociales dependen del modelo de ciudadanía y de la cultura política del país, del contexto sociohistórico en el que se presentan diversas formas de acción e institucionalización, del conjunto de actores sociales y políticos que se enfrentan entre sí como adversarios y del grado de profundización de los conflictos (Tamayo, 2009: 99).

Munck (1995) considera que estudiar los movimientos sociales implica el reconocimiento de tres problemas centrales que se deben confrontar: la formación de los actores, la coordinación social y la estrategia política. La importancia de estos tres problemas es doble. Por un lado, están directamente ligados a la definición de un movimiento social como un tipo de acción colectiva orientada hacia el cambio por una masa descentralizada o grupo de personas encabezadas de manera no jerárquica por un actor social. Esto es, mientras que el problema de la formación de actores atañe a la emergencia de los fundadores u organizadores de un movimiento social, o, en otras palabras, de los actores sociales que organizan y orientan al movimiento social, el problema de la coordinación social tiene que ver con la constitución de un movimiento social como movimiento, con el desafío de organizar a una masa descentralizada o a un grupo de personas de manera no jerárquica; y el problema de la estrategia política está ligado con la orientación de un movimiento social hacia el cambio. Por otra parte, es útil abordar separadamente estos tres problemas porque cada uno suscita un desafío analítico distinto que puede ser elaborado separadamente y visto como bloque fundacional de una teoría abarcadora de los movimientos sociales (Munk, 2005: 24).

El movimiento social en el municipio de Atenco en el Estado de México se definió desde el inicio del año 2001 como contrario a la construcción del aeropuerto internacional de la Ciudad de México, que en su momento se consideró una propuesta urbana que convendría desarrollar en el territorio mexiquense. Es necesario articular este movimiento con los cambios sociales y urbanos que surgieron en el periodo 2001-2011 y así conocer su relación con la propuesta de dicha obra de infraestructura urbana tan importante para el país. Es de señalar que el movimiento social continúa vigente y que el Frente de Pueblos en Defensa de la Tierra (FPDT) sigue en lucha, con menor 
relevancia en el municipio, pero no así en otros espacios locales donde se ha vinculado con múltiples luchas sociales del país y del extranjero relacionadas con la tierra y con los derechos humanos, ambientales, ciudadanos y sociales, entre los más significativos, y que han cumplido ya un decenio de existencia.

Los movimientos sociales en México reflejan la expresión directa e indirecta del conflicto de clases, pero es importante señalar que este caso se trata de una lucha comunitaria, de localidades, más que de una expresión de clase. Su forma depende del estado del sistema político y de la organización social. Cuando se estudia la variación de estas formas no hay que olvidar que los movimientos sociales tienen su razón de ser y se constituyen en el ámbito de las relaciones de clase. En el caso de Atenco se puede identificar un movimiento regional, social, que recibe mayor cobertura y difusión porque su lucha está vinculada con el espacio local, pero también con la defensa de algo "muy delicado": la posesión de la tierra en la Zona Metropolitana de la Ciudad de México.

Alain Touraine (2005) considera que los movimientos sociales son ante todo movimientos culturales, muy diferentes de aquellos cuyas orientaciones socioeconómicas se habían anclado en las sociedades industriales. Tal es el caso de Atenco.

Pero ¿qué tan importantes han sido estos movimientos sociales al iniciarse un nuevo siglo?, ¿qué es lo novedoso de estos movimientos?, ¿a quién sirven? Para el mismo Touraine la contradicción surge entre las fuerzas técnicas y económicas incontroladas y la diversidad de especies y culturas, de actividades locales y de lenguas que contribuyen a formar la subjetividad de cada uno, quien de manera general se subleva contra la negación de su subjetividad y del respeto de sí. El mismo autor considera que el reconocimiento a la diversidad cultural es un elemento fundamental en el análisis de los movimientos sociales, donde el conflicto social central se opone a la globalización de las subjetividades, y en el centro de éstas a la voluntad de ser un sujeto; es decir, de proponerse como objetivo principal para integrar experiencias muy diversas en la unidad de una conciencia de sí que resiste a las presiones y a las seducciones procedentes del exterior (Touraine, 2005: 193).

La idea de modernización ${ }^{2}$ se introduce y se analiza a propósito

\footnotetext{
2 Anthony Giddens et al. consideran que "la modernización" ha funcionado más como razón de Estado y como proyecto político para la transformación económica con una orientación neoliberal, en tanto que "modernidad" engloba un planteamiento más filosófico que al reconocer costumbres, valores y normas, trata de legitimar algo "nuevo" y no formas distintas de hacer lo mismo. La modernidad se identifica como una época delimitada a fines del siglo XVIII cuyos principales protagonistas fueron los franceses
} 
del cambio social; si bien existen movimientos que tienden a pasar del presente al futuro en nombre de la modernización, otros se definen por la lucha en nombre del presente contra el pasado o en defensa del pasado contra un futuro incierto (Giddens et al., 2001: 33-34).

El movimiento social de Atenco no es necesariamente global. El conflicto pudo iniciarse a propósito de un solo elemento, sus características difieren según el lugar o el orden del movimiento; las orientaciones o los recursos, las características sociales o culturales pueden ser determinantes en la definición y estrategia misma de la movilización, que sigue vigente aunque con menor difusión y penetración en la sociedad. Los actores de un movimiento no forman un medio social al que se pueda definir por elecciones comunes, por una identidad social personal y colectiva. Un movimiento social, por el contrario, está constantemente empeñado en poner en entredicho la definición social de los papeles, el funcionamiento del juego político, el orden social.

Para otros el movimiento social parte del hecho de que introduce un ordenamiento social, de que sitúa a la acción social en un espacio intermedio entre el Estado y la sociedad. Para decirlo de otra manera, la presencia del movimiento revela al mismo tiempo la existencia de un conflicto social o cultural y el grado de consolidación de las capacidades democráticas de una sociedad, sobre todo la capacidad de constituirse a partir de ella misma. El movimiento social ejerce así el rol de tipo ideal, de modelo cultural y de principio de comprensión de la realidad (López, 2009: 105).

Es notorio que el movimiento social de Atenco se asocia en gran medida con la organización del FPDT que indudablemente ejerce un liderazgo en la interlocución con varios actores al expresar un discurso social y político mediante acciones y tareas, al organizar movilizaciones que con el transcurso del tiempo han pasado de ser exclusivamente de defensa de la tierra a relacionarse con referentes de carácter económico, de empleo, de seguridad, de derechos humanos y de alcance extralocal manteniendo nexos y vínculos con otros actores que amplían la base de la organización original.

mediante el conocido movimiento de la Ilustración. La modernidad se reconoce como una nueva forma de pensar, en la que se pone mayor atención en la ciencia y la tecnología, así como en los grandes proyectos sociales: el capitalismo y el socialismo, que compartían esos valores. Se considera así mismo que el problema de la modernidad, su despliegue inicial y sus formas institucionales, han reaparecido como cuestión sociológica. 


\section{Lo territorial, lo sociourbano y lo económico}

El municipio de Atenco ${ }^{3}$ se localiza en la parte central del Valle de México y en el oriente del Estado de México; se encuentra separado del Distrito Federal por los municipios de Nezahualcóyotl y Ecatepec. Se ubica a 22 kilómetros de la Ciudad de México y pertenece a la región de Texcoco. Limita al norte con los municipios de Acolman y Tezoyuca, al sur con el municipio de Texcoco, al este con Chiautla, Tezoyuca y Chiconcuac, y al oeste con el municipio de Ecatepec (mapa 1).

Para efectos de gobierno el territorio está integrado por las delegaciones de los pueblos y sus colonias, coordinadas por el Ayuntamiento, que tiene su sede en la cabecera de San Salvador Atenco. En el año 2002 las actividades del gobierno municipal se trasladaron a la comunidad de Santa Isabel Ixtapan como consecuencia de los problemas que derivaron del proyecto del aeropuerto, y en el año 2003 retornaron a la cabecera municipal. Actualmente las actividades del gobierno local se desarrollan de manera normal en las oficinas tradicionales de la cabecera municipal; ahí se ubica también, a un costado, la oficina del Frente de Pueblos en Defensa de la Tierra (FPDT).

\section{Lo sociourbano y lo económico}

$\mathrm{Al}$ iniciarse el conflicto social (2001) no había en el municipio centros importantes de educación, como en Texcoco, pero en el año 2011 ya funcionaba la Universidad Mexiquense del Bicentenario, ${ }^{4}$ a la que se le conoce como la "Unidad Académica Universitaria Atenco", que se ubica en la comunidad Santa Isabel Ixtapan, y que imparte dos licenciaturas: Ingeniería Industrial e Ingeniería en Tecnologías de la Información y Comunicaciones. Para 2010 el territorio contaba con 51 escuelas de diferentes niveles; en el cuadro 1 se presentan sus características. ${ }^{5}$

\footnotetext{
${ }^{3}$ El municipio de Atenco está conformado por las siguientes localidades: Santa Isabel Ixtapan, Nexquipáyac, San Francisco Acuexcomac, Santa Gertrudis, Nueva Santa Rosa, San Miguel, Colonia Guadalupe Victoria, Zapotlán, Colonia Francisco I. Madero y San Salvador Atenco. Pertenece al distrito electoral XXIII estatal, con sede en la ciudad de Texcoco, al que también pertenecen los municipios de Chiautla, Papalotla, Chiconcuac, Tezoyuca, Tepetlaoxtoc y Texcoco.

${ }^{4}$ Esta universidad fue creada por el gobernador Enrique Peña Nieto al final de su administración (2005-2011). La Unidad Académica Universitaria Atenco no tiene vínculos con el FPDT; en el año 2012 egresaron los primeros graduados de dicha institución.

${ }_{5}^{5}$ En lo que respecta a educación, hay 44 escuelas de educación básica (preescolar, primaria, secundaria), tres de educación media superior (bachillerato), y una de edu-
} 
MAPA 1

\section{Ubicación geográfica de Atenco}

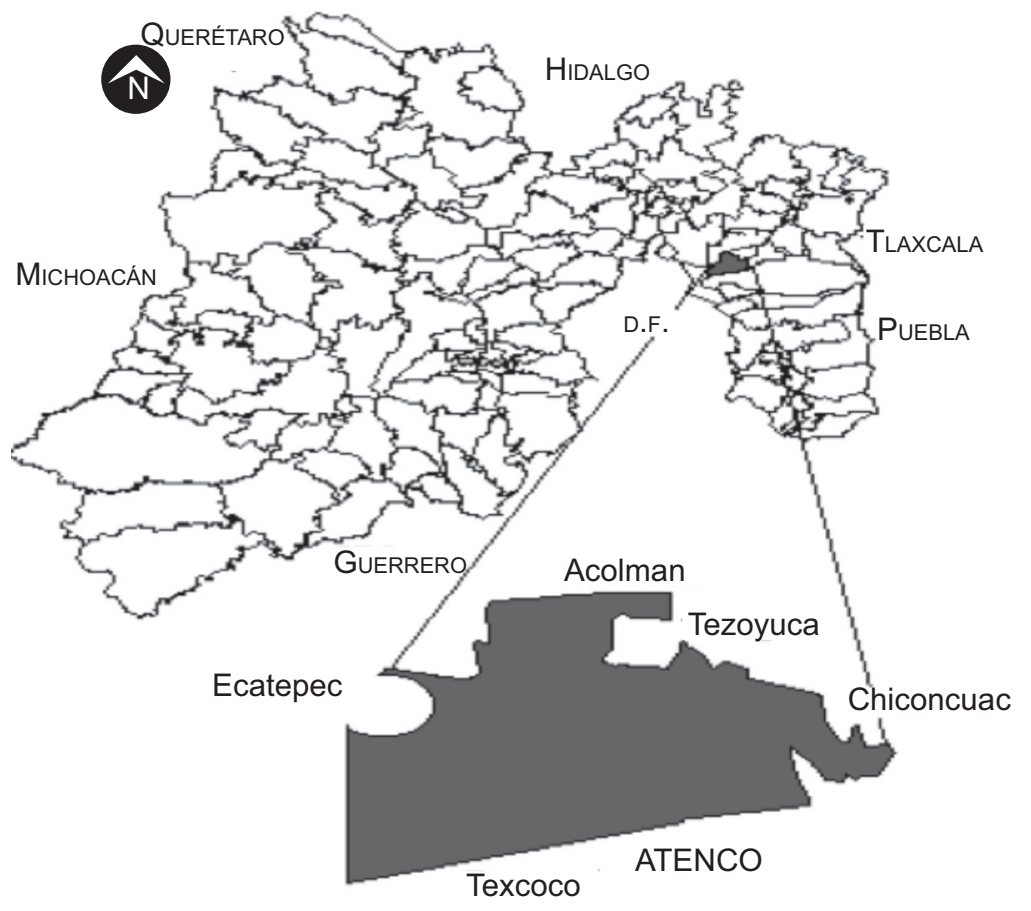

FUENTE: Elaboración propia con imagen del INEGI, 2000.

La configuración educativa de Atenco se modificó en el decenio de 2001 a 2011 con un notable avance en el área al haberse instalado la Universidad y su Unidad Académica, aún limitada, pues su oferta se restringe a dos licenciaturas. Se estima que más del $70 \%$ de los egresados de nivel medio superior (preparatoria o técnica) han de continuar sus estudios en los municipios vecinos, como Texcoco y la Zona Metropolitana de la Ciudad de México.

El reto para el próximo decenio (2010-2020) será dotar a las nuevas generaciones de mayor variedad de opciones de educación superior,

cación superior; hay dos escuelas para la capacitación del trabajo u oficio. Se estima una cobertura de más de $75 \%$ en todos los niveles educativos (INEGI, 2000 y 2010). El municipio cuenta con $96.52 \%$ de alfabetizados. 
ESTUDIOS DEMOGRÁFICOS Y URBANOS, VOL. 29, NÚM. 3 (87), 2014, 541-578

CUADRO 1

Escuelas y universidad en el municipio de Atenco

\begin{tabular}{|c|c|c|c|c|}
\hline $\begin{array}{c}\text { Nivel } \\
\text { preescolar }\end{array}$ & $\begin{array}{l}\text { Nivel } \\
\text { básico }\end{array}$ & $\begin{array}{c}\text { Nivel educación } \\
\text { media }\end{array}$ & $\begin{array}{c}\text { Nivel } \\
\text { superior }\end{array}$ & $\begin{array}{c}\text { Nivel } \\
\text { posgrado }\end{array}$ \\
\hline \multirow[t]{4}{*}{$\begin{array}{l}12 \text { jardines de } \\
\text { niños }\end{array}$} & $\begin{array}{c}13 \\
\text { primarias }\end{array}$ & $\begin{array}{c}2 \\
\text { preparatorias }\end{array}$ & $\begin{array}{c}1 \\
\text { universidad }\end{array}$ & $\begin{array}{l}\text { No } \\
\text { existe }\end{array}$ \\
\hline & $\begin{array}{c}13 \\
\text { telesecundarias }\end{array}$ & $\begin{array}{c}1 \\
\text { preparatoria } \\
\text { abierta }\end{array}$ & $\begin{array}{l}1 \text { centro de } \\
\text { Bachillerato } \\
\text { Tecnológico } \\
\text { (CBT) }\end{array}$ & \\
\hline & 6 secundarias & & $\begin{array}{l}1 \text { Escuela de } \\
\text { Artes y Oficios } \\
\text { (EDAYO) }\end{array}$ & \\
\hline & & & $\begin{array}{l}1 \mathrm{CBT}, \mathrm{en} \\
\text { proceso }\end{array}$ & \\
\hline
\end{tabular}
2011.

FUENTE: Elaboración propia con datos del H. Ayuntamiento de Atenco, agosto de

condición fundamental para el adecuado desarrollo de la localidad y su prosperidad.

En este trabajo, uno de los elementos importantes en la configuración social y urbana es el análisis descriptivo de la población, información que ayuda a generar indicadores sociourbanos que permiten un mejor análisis del movimiento social que aún sigue vigente, ya que facilitan un mejor conocimiento del territorio motivo de la presente investigación. También los patrones de asentamiento de la población tienen implicaciones en las oportunidades de desarrollo y la calidad de vida de las personas; por ejemplo, la Ciudad de México y su zona metropolitana enfrentan dificultades como la escasez de agua y de suelo para el desarrollo urbano, ya que la población contribuye a los desequilibrios territoriales de una localidad, de una región, o en este caso de un municipio, que han de estudiarse con la idea de establecer una mejor articulación de los procesos urbanos, locales, regionales y de ordenación del territorio.

En el censo del año 2000 la población de Atenco fue de 34435 habitantes, y ya para el año 2010 de 56243 personas (INEGI, 2000 y 2010); es decir, en el decenio del conflicto social desatado por la posible construcción del aeropuerto el municipio creció en 21808 per- 
sonas, que equivale a $60 \%$ más de habitantes que en el año 2000. Es preciso especificar que esta cifra no equivale a su tasa de crecimiento poblacional en el periodo señalado. Existe una presión urbana importante, de manera particular en los límites del municipio de Ecatepec, Texcoco y Chiconcuac, con lo cual se ha presentado el mayor crecimiento poblacional en su historia reciente.

El asentamiento urbano se da a partir de la estructura territorial con más de 10 comunidades, pero su mayor crecimiento está en los ejes carreteros Los Reyes La Paz-Lechería, Texcoco carretera de cuota El Peñón. La cabecera municipal de San Salvador tuvo en el año 2000 una población de 17892 habitantes según datos del INEGI, y para el año 2010 se registró un total de 17124 personas en dicha cabecera (INEGI, 2010); es decir, en el periodo de 2001 a 2010 hubo 768 menos habitantes que en el inicio del conflicto social por el proyecto del aeropuerto, lo cual muestra algo inusual en el municipio y es parte relevante de la investigación que se desarrolló en la comunidad. Esto no es nuevo en las comunidades donde existen conflictos sociales o políticos y en los llamados "pueblos abandonados" debido a la inseguridad pública que existe en todo el país.

Sin embargo hay un crecimiento en otras partes del territorio del municipio de Atenco, y ejemplo de ello son las localidades de la colonia El Salado, Granjas Ampliación de Santa Rosa, la cual ha presentado un aumento poblacional de importancia en el último decenio; La Pastoría duplicó su población sólo en el lustro 2005 a 2010 de 2240 a 5135 habitantes. ${ }^{6}$ Atenco creció hacia sus comunidades y no en su cabecera municipal. El cuadro 2 muestra la población que creció de manera importante en algunas comunidades de la localidad; también presenta el grado de marginación y el ámbito de su actividad según el INEGI en el año 2010.

La población de las anteriores comunidades creció en el último decenio más de $70 \%$ respecto al año del conflicto de 2001. En gran medida son comunidades rurales con fuertes vínculos con lo urbano, dada la actividad que desarrollan en el sector terciario de la economía; también presentan un alto grado de marginación toda vez que sus

${ }^{6}$ En breve entrevista con Tonatiuh Martínez Cabrera, asistente del secretario particular del presidente municipal de Atenco 2009-2012, él mencionó que el problema de la delimitación del territorio se relaciona en gran medida con la venta de predios a Conagua, y que hay algunos espacios físicos-territoriales que no están bien definidos. Entrevista realizada el 10 de noviembre de 2011 en las oficinas del Ayuntamiento de Atenco. 


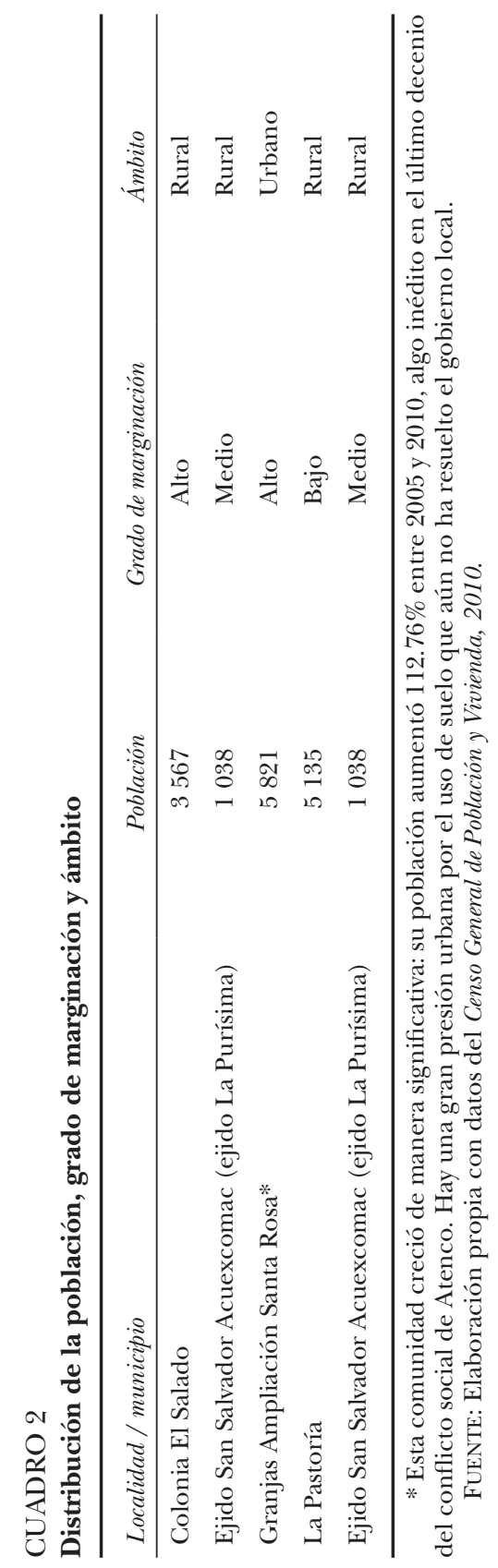


ingresos no superan en promedio 1 a 2 salarios mínimos; es decir, son pobres $^{7}$ por su nivel de ingresos (INEGI, 2010).

Históricamente la cabecera municipal ha sido la localidad con mayor participación poblacional con respecto a la totalidad del municipio, pues ha pasado de $52.35 \%$ en el año 1970 (5 558 habitantes aproximadamente) a $51.96 \%$ en el año 2000, con un total de 17892 personas. En el año 2010 se reportó un total de 17124 pobladores en la cabecera municipal, lo que representó $30 \%$ de la población municipal, una disminución importante del protagonismo poblacional de la cabecera municipal entre 2000 y 2010.

San Cristóbal Nexquipáyac es la segunda comunidad más grande del municipio; pasó de una participación poblacional con respecto a la totalidad del municipio de $18.75 \%$ en 1970 (1 990 habitantes) a $17.75 \%$ en el año 2000 (6 112 habitantes), y en el año 2010 reportó un total de 6661 habitantes, con un leve aumento de 545 personas. En Santa Isabel Ixtapan había 2385 habitantes en 1990, y para el año 2000 eran 4921 -14.29\%-; en 2010 se registraron 4407 pobladores, con una disminución de 514 personas entre 2000 y 2010 (INEGI, 1990, 2000 y 2010).Véase el cuadro 3.

Lo anterior muestra cómo el crecimiento no se ha mantenido uniforme y que existen comunidades que disminuyeron su población. Además se observa una nueva migración intermunicipal, que anteriormente era poca o muy limitada a un número reducido de personas; esto se asocia en gran medida con el conflicto social del 2001 a 2011. En la gráfica 1 se presenta la distribución de la población en el municipio en 2010.

Ya en el año 2000 la morfología de las localidades municipales había cambiado notoriamente; las colonias San Miguel Arcángel y San Miguel Chiconcuac, por ejemplo, actualmente están reconocidas como territorio de Chiconcuac; por otra parte, los asentamientos conocidos como Los Hornos y San Bartolo se han incorporado al área de Santa Rosa. Al oriente del municipio destaca particularmente el caso de la colonia La Pastoría, próxima a la cabecera de San Salvador Atenco, mientras que en el norte la colonia Nueva Santa Rosa, aledaña a la

${ }^{7} \mathrm{El}$ adjetivo "pobres" no tiene connotación despectiva; en todo caso se trata de aclarar que la pobreza es una adversidad socialmente inaceptable. Para muchos economistas el término hace referencia a la privación de los elementos necesarios para la vida humana dentro de una sociedad. Así, la pobreza se puede entender como la carencia de satisfactores para las necesidades elementales, entre los que se pueden mencionar: bienes de consumo (alimentación), de bienestar, de capital físico o humano entre otros. 
ESTUDIOS DEMOGRÁFICOS Y URBANOS, VOL. 29, NÚM. 3 (87), 2014, 541-578

CUADRO 3

Distribución de la población en Atenco en 2000 y 2010

\begin{tabular}{lcc}
\hline Localidad / municipio & Población 2000 & Población 2010 \\
\hline San Salvador Atenco & 17892 & 17124 \\
San Cristóbal Nexquipáyac & 6112 & 6661 \\
Santa Isabel Ixtapan & 4921 & 4407 \\
Total municipio & 34435 & 56243 \\
\hline
\end{tabular}

FUENTE: Elaboración propia con datos del Censo de Población y Vivienda, 2000 y 2010.

población de Ixtapan, ha crecido de forma anárquica y acelerada en los últimos cinco años con asentamientos irregulares (H. Ayuntamiento de Atenco, 2003).

Los procesos de apropiación del suelo en el municipio han dado lugar a una nueva modalidad de acceso a éste por medio de un mercado inmobiliario legal e ilegal, producto de los costos altos de la urbanización y de las dificultades de gran parte de los sectores de la población con menores ingresos. Generalmente este tipo de asentamientos corresponde a lugares no adecuados para un desarrollo urbano y a la carencia de servicios en los predios ejidales o comunales. La tierra destinada para suelo urbano en el municipio de Atenco es de $8.9 \%$, lo que representa 766.79 hectáreas; de ésta $75 \%$ es de uso habi-

\section{GRÁFICA 1}

Distribución de la población por localidad en el municipio de Atenco

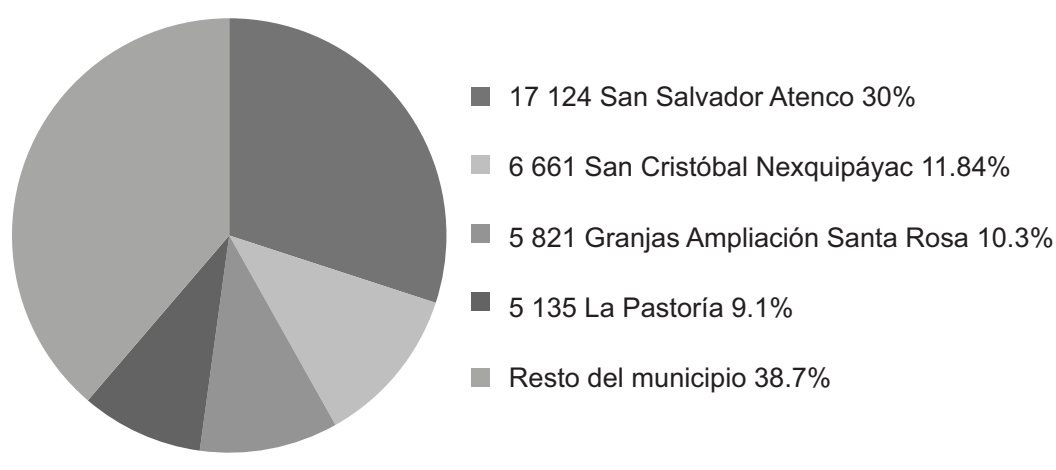

FUENTE: Elaboración propia con datos del INEGI, 2010. 
tacional, $10 \%$ para equipamiento, $3 \%$ para comercio y servicios, $7 \%$ para áreas viales y $5 \%$ son baldíos intraurbanos. El suelo erosionado es $1.4 \%$, lo que representa 132 hectáreas. No se dispone de información relativa al suelo ocioso (H. Ayuntamiento de Atenco, 2003).

Para el municipio de Atenco la problemática de invasiones se acentúa particularmente en el norte y el oriente, sobre los terrenos salinos que antes constituían el Lago de Texcoco y que actualmente limitan con los municipios metropolitanos de Ecatepec y Nezahualcóyotl. Entre los predios invadidos, El Salado, ubicado al norte del municipio, constituye un caso especial, dada la importancia que reviste su peculiaridad en el entorno de las invasiones. La problemática más aguda se contempla en las localidades de Chileco, Las Salinas, Granjas Arenal, Nezahualcóyotl, Benito Quezada, Ejido de Nezahualcóyotl, colonia La Pastoría y Ejidos de San Fermín y San Lazarito en el ejido de Acuexcomac. Dichas colonias no se han regularizado y permanecen en el régimen ejidal, de ahí la necesidad de establecer mecanismos para su regularización. Aún existe un rezago importante en la regularización de usos de suelo urbano en las áreas conocidas como Los Polvorines, Las Longanizas, Los Avioncitos y La Grande. Tampoco se consideran terrenos con orientación urbana El Salado y Sector IV. Falta mayor coordinación entre los gobiernos estatal y municipal para su adecuada regularización.

Gran parte de la superficie municipal se encuentra dentro del régimen ejidal, incluyendo los actuales asentamientos humanos, y un pequeño porcentaje de pequeña propiedad. Los grandes usos de los suelos en Atenco (agrícolas y urbanos) se asientan sobre territorios ejidales, situación desfavorable para el Ayuntamiento, que se ve imposibilitado jurídicamente para incrementar su base gravable respecto al impuesto predial.

Esta situación presenta diversas vertientes de la problemática, ya que las condiciones actuales del campo mexicano no son las más óptimas para la conservación e impulso de las actividades agropecuarias, por lo que su incorporación al desarrollo urbano se da en un marco de entera irregularidad. Además, el retraso de la dotación de los servicios urbanos y del equipamiento urbano colectivo en los centros de población asentados en terrenos ejidales se debe a que su introducción no ha podido ir a la par con el crecimiento descontrolado de los asentamientos humanos. Hoy en día los asentamientos irregulares son uno de los problemas más graves del crecimiento urbano y son también expresión del empobrecimiento de la población. 
Con respecto a la infraestructura urbana y a la cobertura de servicios públicos en materia de vivienda se observa que el territorio municipal registró en 1990 un total de 3699 viviendas, inventario que en el año 2000 alcanzó un incremento neto de 3037 para llegar a 6736 viviendas, lo que representó un incremento relativo de 190\%. En 2010 se registraron 12483 viviendas, con un incremento de 5747 en el decenio del conflicto social de 2000 a 2010, lo que en términos porcentuales significó un aumento de $46.03 \%$ del total de viviendas registradas, con un promedio de ocupantes por vivienda particular de 4.5 personas, lo cual equivale al promedio estatal (INEGI, 2010).

El sistema de agua potable del municipio se compone de nueve sistemas independientes que dotan de agua potable a las comunidades; los servicios son administrados por comités vecinales. Se extraen del subsuelo más de $680 \mathrm{~m}^{3}$ diarios de agua para abastecer a la población municipal. La información contenida en el Plan de Desarrollo Urbano del 2003 refiere que más de 500 viviendas no tienen agua entubada en el municipio, en lo que destaca la localidad de Granjas el Arenal. El abastecimiento a dicha comunidad se realiza mediante pipas particulares, provenientes del Ayuntamiento y otras localidades cercanas como Chiconcuac, Texcoco y Tezoyuca. ${ }^{8}$

En lo relacionado al transporte el municipio no cuenta con ninguna línea local, pero se ha adscrito a diversas líneas de autotransporte que circulan por las comunidades. La principal vía de comunicación es la carretera Texcoco-Lechería, por donde transitan las empresas de autotransporte Valle de México, Teotihuacán y Tepetitlán, cuyas rutas atraviesan el municipio en los principales puntos de acceso vial.

Por lo que se refiere a la infraestructura del sector salud, el municipio cuenta con tres clínicas u hospitales de primer nivel, tres unidades médico-familiares y una unidad básica de rehabilitación e integración familiar. Los hospitales regionales que atienden a los derechohabientes del Instituto Mexicano del Seguro Social (IMSS), el Instituto de Seguridad y Servicios Sociales de los Trabajadores del Estado (ISSSTE) y el Instituto de Seguridad y Servicios Sociales para los Trabajadores del Estado de México y Municipios (ISSEMYM) se ubican en el municipio de Texcoco. El mayor registro se tiene en el IMSS, con 11023 asegurados,

8 Comunidades como El Chileco, ejido de Nexquipáyac, y San Lazarito en el ejido de Acuexcomac, requieren una red de agua potable. En general se observa que en todo el territorio municipal se necesita ampliar las redes de distribución del servicio de agua potable. Actualmente el servicio es irregular en todas las comunidades del municipio y durante la época de secas aumenta considerablemente la carencia del líquido. 
pensionados y dependientes; le sigue el ISSSTE con 4034 derechohabientes y luego el ISSEMYM con 1633 . El personal médico de las instituciones públicas en el municipio es de 25 médicos registrados; ${ }^{9}$ 5 corresponden al IMSS, y 17 al Instituto de Salud del Estado de México (ISEM) (INEGI, 2010a).

La seguridad pública presenta un rezago importante; existe escasa coordinación entre la policía estatal, la municipal y la federal, y prueba de ello son las invasiones que ocurrieron entre 2001 y 2003 en la zona llamada El Salado, limítrofe con el municipio de Ecatepec. ${ }^{10}$

Atenco no cuenta con instituciones financieras en su territorio, no se tiene registro oficial de banco alguno que desarrolle su actividad en la cabecera municipal o en alguna de sus comunidades. Lo anterior es un indicador del proceso de consolidación de la economía de una localidad, ya que municipios vecinos como Chiconcuac y Texcoco tienen diversas instituciones bancarias. Tampoco existen centros comerciales conocidos como "plazas" que también son muestra de un consumo importante y del avance económico de la población en un territorio donde lo local y lo regional expresan en gran medida sus características socioeconómicas.

En Atenco no existe industria relevante que presente un impacto en el empleo o en la economía local; la empresa más importante es Remolques Altamirano de Texcoco, que en su publicidad hace referencia a Texcoco pero en realidad se ubica en el territorio de Atenco. Dicha empresa es conocida nacionalmente por la fabricación, reparación, compra y venta de todo tipo de carrocerías, remolques, y semirremolques. ${ }^{11}$ Atenco es considerado como un municipio de marginación media donde la población ocupada percibe en promedio de uno a dos salarios mínimos (INEGI, 2010). Es decir, el promedio de los habitantes de Atenco son pobres dado el magro ingreso que perciben.

${ }^{9}$ Comprende médicos generales, especialistas, residentes, pasantes, odontólogos. No incluye al personal administrativo.

${ }^{10}$ El municipio cuenta con seis patrullas en promedio para proporcionar el servicio de seguridad pública. Se calcula que hay dos patrullas promedio por cada 11100 habitantes y un policía por cada 1720 . Así, presenta un gran rezago la prevención del delito (Plan Municipal de Desarrollo Urbano 2003 e Informe de labores del año 2003, 2006 y 2009).

11 Esta empresa se amplió en el municipio vecino de Tezoyuca, donde ubicó su nueva línea de producción, y por consiguiente el pago de impuestos se divide en dos municipios, así como los empleos que ofrece. A la fecha se estima laboran 180 trabajadores en distintos niveles, quienes en gran medida son oriundos del municipio de Atenco. 
Los principales indicadores de desarrollo humano en Atenco muestran que el producto interno bruto ${ }^{12}$ fue de 11363.50 pesos a precio de 1993, el índice de desarrollo humano per cápita de $0.8045^{13}$ y el índice de alfabetización de 15 años y más de $0.9617^{14}$ (INEGI, 2010). Estos datos permiten tener un diagnóstico, elaborar instrumentos para diseñar planes y programas, así como evaluar la actuación de los distintos niveles de gobierno en la gestión pública realizada. También ayuda a la caracterización del municipio con variables económicas y sociales antes no estudiadas y que ahora permiten contar con una mejor fotografía del territorio que sigue siendo protagónico por la lucha social emprendida hace un decenio, particularmente en el Estado de México y en general en el país.

En el año 2000 la agricultura sólo empleaba a 693 personas, y en 2010 se reportó un total de 366 personas contratadas para realizar actividades agropecuarias, según datos del censo de 2010. Sin embargo se estima que existen 550 personas que se dedican a esta actividad, aunque es un hecho que los registros muestran un descenso del sector primario. Las unidades de producción son 2364 y según el censo del 2010 hay 919 con actividad agropecuaria y forestal, de las cuales 859 son de tipo agrícola, 45 de cría de explotación de animales, y otra actividad con 24. También se conoce que hay más de 2300 ejidatarios. Los principales cultivos son maíz, frijol, cebada y alfalfa. La superficie es de 3039.61 unidades de producción (hectáreas): 1308.34 con actividad agropecuaria o forestal, y 1731.27 sin actividad agropecuaria o forestal, y por lo tanto la mayor parte de la tierra dedicada al campo no se utiliza para las tareas agropecuarias y forestales (INEGI, 2010).

Siete unidades de producción están integradas en organizaciones de productores cuyos miembros participan como representantes ante otras organizaciones o asociaciones. No hay registros de un consejo municipal de desarrollo rural sustentable, ni de una asociación gana-

12 Con datos publicados al 17 de octubre de 2005 en el Anuario Estadístico de México 2010, tomo I, INEGI / Gobierno del Estado de México.

${ }^{13}$ El INEGI considera que este índice es compuesto y se basa en tres indicadores: longevidad, medida en función de la esperanza de vida al nacer; nivel educacional, medido en función de una combinación de las tasas de alfabetización de adultos y la tasa de matriculación infantil, y el nivel de vida medido por el producto interno bruto per cápita. Anuario Estadístico del Estado de México 2010, tomo I, INEGI / Gobierno del Estado de México.

14 Proporción de la población mayor de 15 años que sabe leer, escribir y comprender un texto corto y sencillo sobre su vida cotidiana. Anuario Estadístico del Estado de México 2010, tomo I, INEGI / Gobierno del Estado de México. 
dera, una asociación campesina o una organización empresarial. El censo del 2010 reporta una sola asociación agrícola en el municipio (INEGI, 2010).

\section{El cambio político}

¿Qué ha ocurrido desde el estallido del movimiento social de Atenco en el año 2001? Han regido tres presidentes municipales, dos gobernadores y dos presidentes de la República. ¿Qué partidos han presidido el municipio y el estado? ¿Qué papel han desempeñado los principales actores políticos en el caso de Atenco?

En el año 2001 el presidente de la República era Vicente Fox, quien presentó la propuesta de construir la mejor obra urbana del sexenio con la instalación del aeropuerto internacional de la zona metropolitana más grande de América Latina. Sería ubicada en territorio mexiquense y específicamente en los municipios de Atenco y Texcoco. Indudablemente Vicente Fox y el entonces secretario de comunicaciones y transportes, el arquitecto Pedro Cerisola Weber fueron los actores principales del proyecto aeroportuario. Los decretos de expropiación de las tierras en la región Texcoco les brindaban facultades constitucionales para construir y operar un aeropuerto. El Estado tiene la facultad de velar por el libre tránsito aéreo de mercancías y personas y su tránsito aéreo o terrestre no se puede limitar a un territorio o a un espacio físico.

También el Ejecutivo federal puede ejercer facultades relacionadas con la regularización, la construcción, la operación y administración, la vigilancia del funcionamiento y demás actos relacionados con las vías generales de comunicación, y es de jurisdicción federal todo lo relacionado con la construcción de aeródromos civiles, así como la facultad de determinar la ubicación de los aeropuertos, para cuya validez no se requiere el consentimiento de los estados o municipios. ${ }^{15}$

El gobierno federal centró su tesis en la necesidad de defender un espacio del Valle de México para la recuperación y ampliación del ex Lago de Texcoco, y a su vez en la de construir el nuevo aeropuerto de

15 Véanse las facultades del Ejecutivo referidas en los artículos 89, fracción I de la Constitución Política de los Estados Unidos Mexicanos con fundamento en los artículos 27, párrafos segundo, quinto y sexto, y fracción VI $2^{\circ}$ de la propia Constitución; $1^{\circ}$, fracciones VII, X y XI, $2^{\circ}, 3^{\circ}, 4^{\circ}, 8^{\circ}, 10^{\circ}, 19^{\circ}$ y $20^{\circ}$ de la Ley de Expropiación, en relación con los Arts. 115 y 27 de la Carta Magna. 
la ZMCM. Más allá de las evidencias técnicas, financieras o urbanas, la construcción de un megaproyecto como el propuesto, que hubiera significado la obra urbana más importante del sexenio del presidente Fox, dio lugar a diversas formas de participación ciudadana de manera formal e informal, comunitaria, organizacional, institucional y autónoma. Con esta experiencia se vivió una nueva relación entre el gobierno y la ciudadanía, donde se puso en cuestión la gobernabilidad y no fue posible la consolidación de acuerdos. Dio lugar a una reflexión mayor suscitada por la importancia de adquirir nuevas experiencias como las de Atenco para lo urbano, lo social y lo ambiental (Moreno, 2008: 167).

El gobernador del Estado de México en el año 2001 era Arturo Montiel Rojas, quien quiso ser candidato por su partido, el PRI, a la presidencia de la República en el año 2006, pero los escándalos por corrupción y tráfico de influencias durante su gobierno le impidieron lograrlo. Fue gobernador de 1999 a 2005. En el año 2001 promovió una gran campaña en los medios de comunicación y los espectaculares en todo el Estado de México del llamado "Proyecto Ambiental Nuevo Texcoco", que según sostuvo se había analizado debidamente desde hacía tiempo (Moreno, 2008: 166). El gobierno del Estado de México impulsó dicho proyecto, el cual requería una serie de tareas y acciones que a la fecha están pendientes, como la construcción de las vías terrestres del Circuito Mexiquense, la ampliación y mejoramiento del enlaceobjetivo Peñón-Texcoco-Calpulalpan-Tlaxcala y el ferrocarril suburbano Valle de Chalco-Los Reyes. Estas obras están contempladas en la administración estatal desde los tiempos de Montiel Rojas. También se recuerda que en esa administración se colocó en las placas de los automóviles del Estado de México la figura de un avión en posición de despegue, y en el fondo los famosos volcanes Popocatépetl e Iztaccíhuatl, representativos del oriente del Estado de México; esta forma promocional continuó en gran parte de la administración local de Peña Nieto.

En el año 2005 hubo un cambio: ascendió a la gubernatura el priista Enrique Peña Nieto con más de 1 millón 800 mil votos, 47.57\% de los sufragios emitidos. Ganó de manera clara, aunque el número de votantes fue inferior a $40 \%$ del total del padrón electoral del Estado de México (IEEM, 2011); así, el abstencionismo fue el gran ganador, porque los partidos y sus candidatos no convencieron al electorado. Durante el periodo 2005 a 2011 Peña Nieto gobernó con cierta tranquilidad la entidad más poblada del país con el apoyo de la clase gobernante de su partido. Él también tuvo que ver con los atencos, y el conflicto que se suscitó los días 3 y 4 de mayo de 2006 en Texcoco y 
Atenco fue más grave que el ocurrido al inicio del problema social por el proyecto del aeropuerto. El tema ya no fue la expropiación de terrenos ejidales, sino la manera de resolver disputas con la "venta de flores" en el mercado Belisario Domínguez ubicado en la ciudad de Texcoco. El conflicto se trasladó a Atenco y derivó en la detención de 207 personas de sexo femenino y masculino, y en graves acusaciones de violación a 26 mujeres. Fue una prueba relevante para mostrar las habilidades políticas de Peña Nieto, su conocimiento del tema y su manera de resolver la problemática social, lo cual no quedó claro y generó una serie de movilizaciones en la región y en la Ciudad de México. Así, el conflicto social continuó.

Para el mandatario estatal de ese entonces y para su partido fue vital superar los malos resultados que obtuvieron en los comicios federales de 2006, cuando el PRI ganó siete de las 40 diputaciones federales, una de ellas en los tribunales. ${ }^{16}$ En ese mismo 2006, el PRI tuvo a nivel estatal 19 diputados de mayoría relativa y el PRD obtuvo el segundo puesto con 17 diputaciones locales, además de dos senadores de mayoría. En ese año hubo elecciones presidenciales y el PAN, con poco margen, obtuvo el triunfo nacional. El PRI tuvo por candidato a la Presidencia a Roberto Madrazo, quien después de su fracaso electoral se retiró del escenario político. Esto confirma que el efecto del cambio de presidente sí influye en los ánimos y en la percepción del electorado, que es el que manda con su voto y transforma un gobierno. El PRD creció en ese tiempo en la región oriente del Estado de México, éxito que se atribuye al "efecto" del candidato a la presidencia de la República, Andrés Manuel López Obrador, también conocido con las siglas de AMLO.

En el año 2006 el Partido Revolucionario Institucional (PRI) fue la tercera fuerza político-electoral en las elecciones federales a la presidencia de la República, por abajo del Partido de la Revolución Democrática (PRD) y del Partido Acción Nacional (PAN), que ganó para el periodo 2006-2012. Aunque en 2006 Andrés Manuel López Obrador perdió la elección constitucional para presidente de la República, el PRD obtuvo dos senadurías de mayoría en el Estado de México con Héctor Bautista y Yeidckol Polevnsky; ${ }^{17}$ pero en 2009 las cosas cambia-

${ }^{16}$ Reportaje de fondo de Leticia Gloria Díaz, "Peña a la compra de votos", publicado en Proceso, núm. 1685, 15 de febrero de 2009.

${ }^{17} \mathrm{El}$ primero se identifica como un actor importante del oriente del Estado, en especial con el municipio de Nezahualcóyotl, donde fue presidente municipal. La segunda fue un personaje de poco arraigo entre los militantes perredistas y se le asoció con el llamado "presidente legítimo", Andrés Manuel López Obrador. 
ron: el PRD perdió gran parte de sus territorios del oriente del Estado de México y el PAN también perdió gran parte del llamado "corredor azul” del norte de la Zona Metropolitana de la Ciudad de México.

El Estado de México es gobernado por el PRI desde hace más de setenta años, y los datos oficiales muestran que es la principal fuerza política en el país en el año 2012, cuando ganó la presidencia de la República. El Estado de México actualmente es la entidad que más votos representa para el país, ya que presenta la lista nominal de 10555669 electores (IEEM, 2011) y una población de 15174272 habitantes (INEGI, 2010), y es muy significativo para el PRI, pero también para el PRD y el PAN. Es conocido el poderío político de los gobernantes mexiquenses y su incursión en diversos ámbitos de la política local y nacional. Los mexiquenses han sido protagonistas de toda una cultura política con su participación en las diversas fuerzas políticas del país. El PRI tiene el reto de establecer una nueva cultura política y de recuperar su fortaleza, como lo demostró en las elecciones presidenciales del año 2012, y también en el año 2011 en las del Estado de México, con el hoy gobernador Eruviel Ávila. El avance esperado de otros partidos como el Partido de la Revolución Democrática y el Partido Acción Nacional fue más limitado en los años 2009, 2011 y 2012. Como ejemplo se puede anotar que de los 41 distritos electorales locales del Estado de México para el periodo 2009-2012, 40 pertenecen al PRI; es decir, el partido en el poder estatal tiene allí una hegemonía absoluta.

Las características políticas de los municipios de la zona oriente del Estado de México están vinculadas en gran medida a la influencia del área metropolitana de la Ciudad de México, pero también ahora existe una mayor influencia del gobierno del estado con sus políticas gubernamentales, y no políticas públicas, que aceptan mayor participación ciudadana; éste no es el caso de Atenco ni el de la mayoría de los municipios del oriente del Estado de México. El PRI se consolidó con el triunfo en la gubernatura estatal de 2011 y con el de la Presidencia de la República en 2012.

Estos indicadores muestran cómo se desarrollan las diversas actividades en la región; asimismo revelan la influencia de la gestión y de las políticas públicas en cada gobierno local. En las elecciones local y federal del 2012 el sistema político mostró el desarrollo de una estrategia en los diversos distritos electorales. Como parte de ésta se acordó que el gobernador del Estado de México ha de mantener márgenes óptimos de gobernabilidad y requiere una representación política que favorezca a su partido en la legislatura local; asimismo se reconoció la 
conveniencia de mantener el mayor número de representantes en la Cámara de Diputados en las elecciones federales y contar con capacidad de negociación en un congreso mayoritariamente priista. ${ }^{18} \mathrm{Si}$ bien en esta región oriente del Estado de México hay presencia de dos partidos, el PRI y el PRD, la lucha política se transformó a partir de que el PRI tuvo un "fuerte" gobernador del Estado de México y un presidente de la República en el año 2012, Enrique Peña Nieto.

En el caso particular de Atenco, ubicado en la región oriente del Estado de México, los partidos políticos que tienen presencia y representan a las distintas fuerzas políticas han transformado el tejido y la conformación del municipio y del distrito electoral local y federal e influyen en las cámaras local y federal. A la fecha destaca la presencia en el municipio de dos fuerzas políticas: por un lado el PRI, que allí gobierna y que en las pasadas elecciones de julio de 2009 y 2012 ratificó su triunfo y ha sido hegemónico en el periodo analizado; la segunda fuerza política es el Partido Convergencia.

En mayo de 2006 era presidente de Atenco el ingeniero Pascual Pineda Sánchez, de extracción priista, cuya posición fue poco congruente con la de sus vecinos en el conflicto del 3 y 4 de mayo de ese año respecto a las acciones y tareas que emprendió el ejecutivo estatal. En el gobierno federal continuaba el presidente Vicente Fox Quesada, a quien le quedaban seis meses en el poder y no ejerció acciones de represión en contra de los atencos; la decisión fue de orden local y en gran medida la tomó el gobernador mexiquense. No se sabía quién sería el sucesor de Vicente Fox, aunque las encuestas favorecían por casi diez puntos a Andrés Manuel López Obrador, pese a lo cual perdió ante Felipe Calderón Hinojosa (2006-2012), que también debió hacerse cargo del asunto de los atencos y recibió diversas quejas de orden local, estatal y federal.

En el año 2006 era presidente municipal interino de Texcoco Nazario Gutiérrez Martínez, ${ }^{19}$ a quien le tocó el conflicto de los ven-

18 Así ocurrió en el año 2009, cuando el PRI fue mayoría en el Congreso de la Unión y en el Congreso estatal del Estado de México. La configuración local en 2012 reporta que el PRI logró la mayoría de los municipios mexiquenses y de los diputados locales en el congreso mexiquense. El Estado de México sigue manteniendo gran importancia para el PRI. Sin embargo Camacho Solís (2011) considera que en 2000 y 2006 el PRI perdió la elección presidencial local porque el arrastre de las candidaturas de Fox, AMLO y Felipe Calderón y las alianzas no compitieron entre sí, sino que compitieron contra el PRI. Si los ciudadanos juzgan posible derrotar al partido en el poder irán a votar, por lo cual ésta sería la única manera de hacer que fracasara el partido que ha venido ganando (Camacho, 2011).

${ }^{19} \mathrm{Al}$ expresidente municipal Nazario Gutiérrez se le identifica con el médico Higinio Martínez Miranda y su grupo político (GAP), mismo que fue electo para el periodo 
dedores de flores en el mercado Belisario Domínguez; el 3 de mayo de 2006 envió a la policía local a que solicitara a los vendedores que se retiraran de un lugar que no les correspondía, toda vez que invadían un espacio destinado a los locatarios originales; esto derivó en una trifulca entre la fuerza pública y los atencos y sus machetes. La posterior actuación de los principales líderes del FPDT derivó en un conflicto mayor. Las fuerzas estatales y federales intervinieron el 4 de mayo de 2006 ya no en Texcoco, ahora en Atenco; murieron dos personas, fueron detenidas 207, y hubo acusaciones graves de violación de 26 mujeres. Dicho conflicto se ha conocido en el mundo entero; lo han abordado la Corte Interamericana de Derechos Humanos (CIDH), la Comisión Nacional de Derechos Humanos (CNDH) y diversas comisiones locales municipales y estatales. El asunto de Atenco que ocurrió en 2006 puede ser considerado como el tema de Atenco II, ya que el Atenco I se identifica con el conflicto por la oposición al aeropuerto en la región Texcoco, con especial énfasis en ese municipio.

Pero en agosto de 2006 había ya nuevos ediles en Texcoco y Atenco, además de nuevo diputado local en el distrito XXIII, con sede en Texcoco. El presidente municipal de Texcoco era de origen perredista y recientemente había ingresado al gobierno local de Atenco otro presidente perredista; el gobierno estatal era priista y el gobierno federal panista, es decir, las principales fuerzas políticas y distintos niveles de gobierno se involucraron en el asunto local, que es conocido a nivel nacional e internacional. Nuevamente la opinión se dividió: unos estaban a favor de la ley y el estado de derecho, y otros lo observaban como una de las faltas más graves de la conducción de una entidad y de la carencia de derechos humanos. Así, el tema de Atenco continúa no por la construcción del aeropuerto, sino por otras reivindicaciones sociales, políticas y de defensa de una forma de vida y de seguridad, y también por una manera de apreciar y entender una forma de gobierno en una localidad y una región divididas y con escasa identidad mexiquense.

En los medios de comunicación y en la región de Texcoco ha quedado la impresión de que Atenco II fue más grave que Atenco I debido al número de muertos, a las detenciones y a las violaciones. Un conflicto que parecía más sencillo que el del aeropuerto se complicó por la venta de flores en Texcoco; a la fecha se le considera un conflic-

2003-2006 en Texcoco y no terminó su periodo, ya que buscó la diputación plurinominal para el periodo 2006-2009 por el PRD en el congreso estatal. 
to "político" donde el gobernador mexiquense mostró fuerza pero también poca experiencia en la negociación, así como un escaso conocimiento de la región, de las localidades y de un entorno local propicio para los movimientos sociales de una nueva era. Llama la atención que tras este conflicto ganara nuevamente un priista el gobierno local para el periodo 2009-2012.

Atenco pertenece al distrito electoral XXIII estatal con sede en la ciudad de Texcoco. ${ }^{20}$ Para el periodo 2009-2012 se eligió como presidente municipal a Mario Ayala Pineda, de origen priista. Al final de su periodo se considera que una de las tareas más importantes que llevó a cabo fue consolidar obra pública en diversas comunidades, entre las que destaca la fundación de la Unidad Académica de la Universidad Mexiquense en Ixtapan, con apoyo significativo del gobierno del Estado de México. Además buscó un mejor acercamiento con el FPDT, aunque no lo logró durante su mandato. Los procesos electorales del decenio 20002010 en el municipio y en la región no fueron ajenos a las características del sistema político mexicano, que también intervino en la propuesta urbana para la región. En el cuadro 4 se presentan los resultados electorales del municipio y del distrito local del periodo 1996 a 2009.

Se estima que el nivel de abstencionismo en la elección de gobierno local fue superior a $55 \%$ de los posibles votantes en el decenio 2000-2010. En el análisis político destaca el distrito local XXIII, al cual pertenece Atenco. El PRD obtuvo el triunfo en el municipio y el distrito local en el año 2006, y esto se asocia al momento político que determinó el conflicto del mes de mayo de ese mismo año, conocido como Atenco II. En el ámbito local el PRD ha triunfado en las elecciones de 1996, de 2000 y de 2006, cuando logró hegemonía en el distrito electoral estatal al que pertenece Atenco. Sin embargo el PRI fue hegemónico en el ámbito municipal en 1996, 2000, 2003 y 2009. En 2012 el PRI nuevamente obtuvo el triunfo municipal y distrital (tanto estatal como federal). El PAN no logró ganar este distrito local en el periodo analizado ni tampoco la presidencia municipal. Para los pobladores de Atenco la represión de mayo de 2006 tuvo un efecto negativo y así lo demostraron con el voto local favorable al PRD así como el del distrito local estatal.

${ }^{20}$ A este distrito pertenecen los municipios de Atenco, Chiautla, Papalotla, Chiconcuac, Tezoyuca, Tepetlaoxtoc y Texcoco, y también al distrito electoral v federal, con sede en San Juan Teotihuacán. Este distrito está ubicado en el extremo noreste del territorio del estado; lo conforman los municipios de: Acolman, Atenco, Axapusco, Chiautla, Chiconcuac, Nopaltepec, Otumba, Papalotla, San Martín de las Pirámides, Temascalapa, Teotihuacán, Tepetlaoxtoc y Tezoyuca. 
ESTUDIOS DEMOGRÁFICOS Y URBANOS, VOL. 29, NÚM. 3 (87), 2014, 541-578

CUADRO 4

Resultados de las votaciones locales de 1996, 2000, 2003, 2006 y 2009 en el municipio de Atenco

\begin{tabular}{|c|c|c|}
\hline \multicolumn{3}{|c|}{1996} \\
\hline Partido & Diputados locales & Presidencia municipal \\
\hline PRI & 29576 & 3241 \\
\hline PAN & 10268 & 1706 \\
\hline PRD & 33768 & 3068 \\
\hline \multicolumn{3}{|c|}{2000} \\
\hline Partido & Diputados locales & Presidencia municipal \\
\hline PRI & 40575 & 4519 \\
\hline PAN & 22866 & 2516 \\
\hline $\mathrm{PRD}^{\mathrm{a}}$ & 40908 & 2191 \\
\hline \multicolumn{3}{|c|}{2003} \\
\hline Partido & Diputados locales & Presidencia municipal \\
\hline $\mathrm{PRI}^{\mathrm{b}}$ & 29027 & Nulidad $^{c}$ \\
\hline PAN & 12505 & Nulidad $^{c}$ \\
\hline PRD & 26118 & Nulidad $^{c}$ \\
\hline \multicolumn{3}{|c|}{2003 Elección extraordinaria } \\
\hline Partido & & Presidencia municipal \\
\hline PRI-PVEM $^{\mathrm{d}}$ & & 5302 \\
\hline PAN & & 832 \\
\hline PRD & & 3689 \\
\hline \multicolumn{3}{|c|}{2006} \\
\hline Partido & Diputados locales & Presidencia municipal \\
\hline PRI & 29576 & 2805 \\
\hline PAN & 10268 & 822 \\
\hline PRD & 33768 & $3580^{\mathrm{e}}$ \\
\hline
\end{tabular}


CUADRO 4

(concluye)

\begin{tabular}{lcc}
\hline \multicolumn{3}{c}{2009} \\
\hline Partido & Diputados locales & Presidencia municipal \\
\hline PRI $^{\mathrm{f}}$ & 64281 & 5448 \\
PAN & 11042 & 740 \\
PRD & 46369 & 1589 \\
Convergencia & & $4963^{\mathrm{g}}$ \\
\hline
\end{tabular}

${ }^{a}$ El PRD obtuvo un reducido margen de victoria en el distrito XXIII, con tan sólo el $0.28 \%$ sobre el PRI.

${ }^{\text {b }}$ La alianza PRI-PVEM le ganó al PRD el distrito electoral.

c Resolución de los juicios JI/157/2003 y JI/158/2003 acumulados, donde se determinó la nulidad de la elección. 9 de marzo de 2003.

d La alianza PRI-PVEM ganó la elección extraordinaria celebrada el 12 de octubre de 2003. El costo de esta elección fue superior a los 900 mil pesos. XXIII.

e Es la primera ocasión que el PRD ganó la elección municipal y además el distrito

f Coalición "Unidos para cumplir", integrada por el PRI, Verde Ecologista, Nueva Alianza y Partido Social Demócrata.

${ }^{\mathrm{g}}$ Es la primera ocasión en que Convergencia se aproxima a ganar la presidencia municipal, ya que perdió con sólo 3\% respecto al PRI.

FUENTE: Instituto Electoral del Estado de México. Resultados de las elecciones de los años 1996, 2000, 2003, 2006 y 2009.

\section{El movimiento social del FPDT}

Es indudable que las características de los municipios de la región oriente del Estado de México presentan diferencias sociopolíticas propias de cada región; es evidente la influencia de la Ciudad de México en cada aspecto social y político. "El proyecto aeroportuario" para la zona metropolitana más grande del país se inició con los decretos expropiatorios del 22 de octubre de 2001, que habrían de afectar a un número importante de ejidatarios de los municipios de Atenco, Texcoco y Chimalhuacán y sus núcleos agrarios, así como el uso de suelo.

En ese momento de la historia del Estado de México surgió el Frente de Pueblos en Defensa de la Tierra (FPDT) para organizar las demandas fundadas en la defensa de los predios expropiados en los ejidos de San Felipe, Tocuila, La Magdalena Panoaya y Cuautlalpan pertenecientes al municipio de Texcoco; también se organizaron para la defensa de los ejidos de San Salvador Atenco, Nexquipáyac y Acuex- 
comac, ubicados en el municipio de Atenco; sin embargo no todos los ejidatarios de Atenco participaron en el movimiento social; tal fue el caso del ejido de Santa Isabel Ixtapan, que no participó y que en el año 2002 exteriorizó su apoyo al presidente municipal en turno, de ahí que las oficinas del Ayuntamiento se trasladaran de manera provisional a dicha comunidad (Moreno, 2008: 161). El FPDT no integró a estas demandas al ejido de Santa María Chimalhuacán en gran medida porque se suele considerar que es una localidad cuya identidad es ajena a la de la región Texcoco. Chimalhuacán se ve como una región más urbana y con una presencia política asociada al PRI y a sus estructuras o poderes fácticos (tal es el caso de la organización política "Antorcha"), de ahí que no se buscara un acercamiento con los ejidatarios de esa localidad.

Los líderes más conocidos del FPDT en el decenio 2001-2011 eran: Ignacio del Valle Medina, Adán Espinosa, David Pájaro Huertas y la hija de Ignacio del Valle, América del Valle, quienes en su momento encabezaron el movimiento, el cual adquirió mayor o menor notoriedad según el momento calendárico. Originalmente lo constituyeron ejidatarios de Atenco y de Texcoco, así como de los núcleos agrarios que afectó el decreto expropiatorio de 2001. Luego, con los años se han ido integrando otros grupos sociales de diversa índole, como asociaciones de obreros, estudiantes universitarios y profesores de universidades públicas; tales son los casos de la Universidad Autónoma Chapingo y de la Universidad Nacional Autónoma de México, entre las más conocidas. Al FPDT se asociaron en su momento organizaciones nacionales como el Sindicato Mexicano de Electricistas (SME) y el Frente Popular Revolucionario (FPR), que se aliaron en la lucha social con diversos propósitos, como el empleo y la seguridad social, pero no ha habido una alianza directa con algún partido político en específico. También participan grupos sociales y organizaciones no gubernamentales tanto nacionales como internacionales. Entre los organismos internacionales destacan Human Rights, Comisión Interamericana de Derechos Humanos, Heart Voice, y diversas redes internacionales dedicadas a la defensa de los derechos humanos en Italia, Canadá, Francia, España y Estados Unidos.

En el movimiento de Atenco intervienen campesinos y ejidatarios de dicha localidad, pero también diversos actores sociales, económicos, ambientales y políticos. Los campesinos dedicados a la actividad agrícola en este poblado no fueron los únicos que protagonizaron el movimiento social: participaron grupos estudiantiles, obreros, organi- 
zaciones urbanas, grupos ambientalistas y de derechos humanos e incluso organismos que defienden la vivienda y el desarrollo urbano; tal fue el caso del alto comisionado y relator para la vivienda de la Organización de las Naciones Unidas. ${ }^{21}$ Así, el movimiento de Atenco no puede inscribirse de manera exclusiva como campesino, de jornaleros o de productores.

¿Cuál es su prioridad?, ¿cuáles son sus estrategias? Tras el trabajo de campo y las entrevistas que realizamos podemos concluir que entre varios de sus miembros predomina la idea de defender su tierra, su campo y su estilo de vida, de dar mayor valor a su tierra, ya que cada día es más difícil insertarla en las cadenas productivas del mercado y del capital. Sus estrategias han estado vinculadas a una lucha social que abarca grupos urbanos de distinta índole (SME, maestros, estudiantes, empleados, campesinos, ONG nacionales e internacionales, entre los más destacados). El conflicto por el uso del suelo es una realidad que experimentan los miembros del FPDT y que se asocia con lo político, y tanto en Atenco como en la región varios pobladores identifican con una misma cara a la política, el gobierno y la gestión. Sin embargo en la problemática social hay distintos referentes, por ejemplo, "Antorcha" 22 no era relevante en el pasado inmediato, pero hoy esta organización priista es una realidad en Atenco, ya que los miembros del FPDT no consideraron la influencia de este tipo de organizaciones en su territorio. El FPDT no se creó para gestionar obra o servicios públicos, sino para fomentar un estilo de vida fincado en el campo, en la agricultura, en la producción de autoconsumo y en el arraigo a su tierra; sus estrategias y sus principales miembros no se identifican con la lucha por el poder local ni con los partidos políticos o las organizaciones

${ }^{21}$ El encargado de la ONU para atender los asuntos del derecho a la vivienda en nuestro país durante los años 2002-2003 fue Miloon Kothari. Escuchó los reclamos que expresaron los miembros del Frente de Pueblos en Defensa de la Tierra sobre la inestabilidad social. También el relator de las Naciones Unidas recordó que en la administración de Vicente Fox existían instrumentos internacionales que el gobierno había firmado y aceptado, los cuales protegen los derechos de los mexiquenses y de manera concreta de los ejidatarios atenquenses (nota publicada en el periódico La Jornada de 7 septiembre de 2003).

${ }^{22}$ Se considera que el grupo "Antorcha", antes conocido como "Antorcha Campesina”, preside demandas sociales de los sectores populares y de bajos ingresos. También dicho grupo se vincula como parte de la estructura territorial del PRI; tiene injerencia y participa activamente en la política electoral en ciertas regiones del Estado de México y del país. El municipio de Chimalhuacán es uno de sus bastiones más importantes en la región oriente del Estado de México. En Atenco, Antorcha es una realidad en el año 2012, y deberán lidiar con esta organización algunos de sus habitantes, el gobierno local y el FPDT. 
asociadas a éstos. El FPDT no tiene relación directa con el gobierno local o estatal, lo cual no excluye que ejerzan presión sobre los gobiernos local, estatal y federal en donde los actores, los grupos y las organizaciones manifiestan un fin político. En entrevista del autor (2008) con David Pájaro Huertas, uno de los líderes del FPDT, éste expuso:

Tengo la evidencia suficiente para decir que alguien como yo no debe vender su tierra; tengo fuerte arraigo a ella. Como nota, me hacen ejidatario como muchos en México, sin que hubiera nacido ahí. A mis 15 años mi padre dijo en una asamblea: "quiero una parcela porque tengo varón". A los 25 años, mi padre dijo: "David vas a atender esa parcela, ¿sí o no?”. Sí la voy a atender [...] llevo 20 años con lo que aprendí en mi formación básica en suelos, después de la licenciatura [...] veo que la única manera que tenemos nosotros los pobladores ribereños del ex Lago de Texcoco de mostrar que no vamos a vender a ningún precio es llegar y establecernos y mostrar al mundo que esas tierras que están catalogadas de inservibles sí sirven, y no nos pueden sacar de nuestra circunstancia." ${ }^{23}$

Lo anterior expresa en gran medida el sentir de los miembros del FPDT, su identidad, sus principios, su lucha, su condición cultural, sus reivindicaciones económicas y su estrategia con miras a conservar cierto tipo de vida y de organización. Parece una crítica a una racionalidad económica vigente, cuestiona la globalización y la modernidad y se asocia con un tipo de desarrollo que no necesariamente comparten todos los pobladores de Atenco o la región. Son argumentos de interés que el FPDT ha defendido en este último decenio en múltiples ocasiones.

El asunto del aeropuerto en Atenco y en la región Texcoco tuvo un efecto mediático nacional, regional y local, y de manera particular para el FPDT, y se difundió en un escenario mundial que antes escasamente se había conocido. Posteriormente, en el año 2006, nuevamente Atenco y el FPDT volvieron a ser noticia internacional por la detención de más de 200 personas, por los muertos y por las violaciones a los derechos humanos que resultaron de un conflicto que se inició el día 3 de mayo con la venta de flores en Texcoco.

Hasta el año 2012, tras un decenio del conflicto social que llevó a la cancelación del proyecto aeroportuario más importante para el país, la región y el Estado de México, que ahora se encuentra detenido, se

${ }^{23}$ Lo anterior es parte de la entrevista a David Pájaro Huertas y aparece en el texto: Un estudio social, urbano y ambiental de los municipios de Texcoco y Atenco. El caso del proyecto del aeropuerto internacional en el Estado de México, de Enrique Moreno, IAPEM, 2008, p. 212. 
observa que en dicho megaproyecto las consideraciones ecológicas o políticas no fueron las suficientes para detener un plan de tal naturaleza. El problema de Atenco tomó otro sentido en 2006 con la represión que ejercieron en mayor medida el gobierno estatal y el ejecutivo del mismo. El movimiento social ha continuado con menor impacto en Atenco, no así en otras latitudes o en la ZMCM, donde se le reconoce como un "movimiento social", en el que participan varios actores sociales y políticos. Esto sigue, pero la cuestión ya no se limita a discrepancias entre el gobierno federal y los ejidatarios, quienes portan machetes como defensa y como icono ya no de la tierra, sino de las demandas ciudadanas de justicia, libertad, derechos humanos, empleo y seguridad, entre otras. Cabe recordar que cada movimiento social se asocia con el dato social mismo y con los procesos culturales históricos que son fruto de una democracia y de una racionalidad en un momento determinado.

Como parte de la investigación presentamos la entrevista con el señor Miguel Ángel Rodríguez, encargado de gobernación del Ayuntamiento de Atenco, que realizamos el 26 de agosto de 2011. Expone su opinión conforme a la perspectiva particular de una posición política del gobierno municipal, ${ }^{24}$ la cual seguramente difiere de la de los gobiernos anteriores y el actual, pero fue una opinión con una visión que en ese momento histórico experimentó un funcionario municipal de Atenco dentro del gobierno local.

Pregunta: Señor Miguel Ángel: ¿Qué ha pasado desde el 2001 a la fecha y qué sucede con el FPDT?

Respuesta: No puedo hablar de otras administraciones, sino de lo que hemos trabajado, que es del 2009 a la fecha. El señor presidente [Mario Ayala] ha tenido mucha capacidad para el diálogo con el Frente de Pueblos; ellos están acostumbrados a hacer y deshacer. En pasadas administraciones agredieron, machetearon, abrían puertas de la presidencia... esto ha cambiado totalmente. Estaban acostumbrados a tener asambleas públicas; bajo y les digo “¡se acabó!, ¡la próxima va a ser arriba!”. El presidente ha tenido capacidad para dialogar con ellos; a base de diálogo nosotros como gobernación hemos tenido esa capacidad, tenemos amistad con ellos, hemos dialogado, hemos llegado a un mejor trato. Esa

${ }^{24}$ Cabe mencionar que la presente es una parte de la entrevista que realizamos en la planta baja de las instalaciones del Ayuntamiento de Atenco el 26 de agosto de 2011, donde el PRI gobernó el municipio en el periodo 2009-2012, también en el distrito local y federal al que pertenece dicho municipio en dicho periodo, y además en el periodo 2012-2015. 
agresividad que ellos tenían se acabó, con nosotros ha sido diferente, con base a diálogo, convenios con ellos, el presidente ha sido habilidoso y llega siempre a un buen arreglo con ellos. Sí ha habido en otro momento conflicto con obras, pero se ha llegado a acuerdos.

Pregunta: ¿Cómo ha sido el trato con el gobierno del Estado?

Respuesta: Bastante bueno; mire, el presidente ha madurado mucho.

Pregunta: ¿Ha venido Peña Nieto?

Respuesta: No lo hemos podido bajar aquí, por el temor que tienen ellos por el conflicto, pero el gobierno del estado nos ha ayudado mucho en las obras; nosotros el año pasado metimos 87 millones en obras, de gestión, como de presupuesto que nos da el gobierno del estado y aparte de ello nos han apoyado con cemento [...] mucho apoyo para el municipio de Atenco. Se está viendo un cambio total, se refleja con las obras.

Pregunta: ¿Algunos predios ya se vendieron a la Comisión Nacional del Agua (Conagua) por lo del proyecto ecológico?25

Respuesta: Esto fue un convenio de los ejidatarios de Santa Isabel Ixtapa y de Nexquipáyac; una parte ya se vendió, pero ahora ya no se vendió a 7 pesos, sino a 157 pesos metro cuadrado de ejido. Casi se dieron 4 millones 700 mil pesos por ejidatario; tres hectáreas de cada ejidatario son en total aproximadamente 1400 hectáreas para el proyecto del Lago, de los humedales; ése fue el convenio a que llegaron los ejidatarios con Conagua. Está pendiente una parte de Acuexcomac, de Atenco y la Madero que la gente va a vender... le voy a dar una explicación, en el pueblo de Nexquipáyac 17 ejidatarios no quisieron vender porque son del FPDT.

Pregunta: ¿Se dividió la población hace unos años?

Respuesta: Sí, hasta la fecha está dividida aquí también, entre familias y vecinos. Aquí se ha tratado de hacer mucha obra, pero si los del Frente no dejan, el presidente se la lleva a otro lugar.

Lo anterior permite conocer la opinión de un representante del gobierno municipal en Atenco conforme a su perspectiva personal en el año 2011. El conflicto de Atenco comenzó en el año 2001 por el asunto del aeropuerto y continuó en mayo de 2006 por la venta de flores en un mercado de la ciudad de Texcoco, problema que se trasladó a San Salvador Atenco. Tras más de un decenio del fallido proyecto de construcción del mayor aeropuerto en México es posible

${ }^{25}$ Conviene mencionar que dentro del proyecto "Ambiental Nuevo Texcoco", que impulsó el entonces gobernador del Estado de México Arturo Montiel Rojas entre 1999 y 2005 se consideró la ampliación de la zona federal del ex Lago de Texcoco; también aparece en el decreto expropiatorio del 22 de octubre 2001 para el asunto del proyecto del aeropuerto en Texcoco, donde se consideró la ampliación de los límites del actual Vaso del Lago de Texcoco para construir obras hidráulicas que permitan mantener mejor equilibrio ecológico de la región. 
hacer una mejor reflexión, análisis y discusión acerca de las consecuencias que puede acarrear la construcción de un megaproyecto urbano, como en ese caso la construcción de un nuevo aeropuerto internacional para la ZMCM. Para emprender obras de este tipo se requieren estudios y análisis de la situación social, de las condiciones políticas, de la cultura, de los usos y costumbres de un municipio y de una región. En la infraestructura urbana de hoy interviene todo un desarrollo local y regional, por lo tanto la propuesta de obras públicas de gran magnitud requiere estudios y trabajos complementarios de planificación urbana, social, ambiental, sociológica y política. En el año 2011 se reconoció que buena parte de los ejidos que estuvieron en conflicto en el año 2001 se vendieron a Conagua, y según la versión oficial esto es parte de un proyecto ecológico de gran envergadura ambiental, urbana y social que coordinan la Comisión del Lago de Texcoco (CLT) y la Secretaría de Medio Ambiente y Recursos Naturales (Semarnat). El análisis documental y empírico comprueba que lo expuesto en el decreto de expropiación del 22 de octubre del 2001 y la propuesta original del Proyecto Ambiental Nuevo Texcoco ${ }^{26}$ están vinculados con las obras de infraestructura hidráulica y terrestre considerada en el año 2001, y que una parte de éstas se está llevando a cabo. Queda abierta la pregunta: si no hay aeropuerto, ¿se continuarán las obras consideradas en los documentos antes mencionados?

\section{Conclusión}

Atenco se ha asociado con el movimiento social que en su momento se opuso a la construcción de un megaproyecto urbano mediante una acción conflictiva entre actores que defendían distintos intereses, incluso contrapuestos, lo cual ocasionó tensiones, protestas y movilizaciones. Sin embargo en el año 2006 el movimiento social que tiene otro sentido se inició en Texcoco con la venta de flores en un mercado, y no en Atenco, municipio que en este último decenio ha protagoni-

${ }^{26}$ En el "Proyecto Ambiental Nuevo Texcoco" se incluyó en el año 2001 una serie de trabajos a realizar en una superficie de 20 mil hectáreas, entre los que destacan la recuperación de suelos, la instalación de plantas tratadoras de agua, la construcción de cuerpos de agua, la reforestación, el desarrollo de vialidades mexiquenses, la ampliación de carreteras y libramientos, la construcción de trenes suburbanos, entre otros; lo anterior se analiza en el texto Un estudio social, urbano y ambiental de los municipios de Texcoco y Atenco. El caso del proyecto del aeropuerto internacional en el Estado de México, de Enrique Moreno, IAPEM, 2008. 
zado el conflicto social en mayor medida. Hay múltiples cuestionamientos sobre estos movimientos: para algunos sectores de la sociedad mexicana su demanda es incomprensible; para otros es el resultado del problema del campo que vive nuestro país en torno a la venta de productos, el cual en este caso adquiere relevancia porque se trata de una zona cercana a la gran ciudad y ubicada en el área metropolitana más grande del país.

La cuestión urbana y el conflicto social propio de las grandes zonas metropolitanas ahora son el escenario de las nuevas luchas sociales, ya que las obras urbanas adquieren una dimensión no tradicional y el conflicto social y político puede ser determinante en el devenir histórico. Este conflicto social que lleva más de una década, ahora se presenta con un nuevo cariz que deriva de una manera "apolítica" de hacer política y de influir en decisiones políticas que transforman una realidad social, como secuela de un proyecto urbano y de un conflicto con organizaciones (FPDT) cuya acción en el gobierno local y federal ha sido escasamente evaluada y analizada en sus características social, urbana y política y en la de los diversos actores que intervienen.

Atenco ha tenido que enfrentar un desarrollo urbano poco ordenado y mal planeado en sus distintas localidades y acostumbrarse a él; esto ha requerido una mayor dotación de servicios públicos (agua potable, energía eléctrica, drenaje, entre otros); la redefinición de la población en su territorio, y el cambio de uso de suelo en el último decenio de agropecuario a urbano, semiindustrial o comercial. Este municipio se ha convertido en una extensión de la gran ciudad, toda vez que se entrelazan sus tradiciones, sus formas de organización, sus expresiones culturales, sus valores y las formas de vida de sus pobladores, quienes reciben la influencia de la región y de una modernidad donde los distintos actores se estructuran a partir de cierta identidad, de ciertos principios, con la condición sociocultural y las características de una zona que pertenece al Estado de México, pero recibe la influencia determinante de la metrópoli más importante del país y de Latinoamérica.

En Atenco los ejidos se han visto presionados por el crecimiento demográfico natural y por la población migrante que busca nuevas alternativas; ahora la venta de tierra ejidal es una realidad, ya que buena parte de los predios que no se vendieron en 2001 para el proyecto del aeropuerto los ha adquirido Conagua, para mitigar la gran presión urbana por el uso de suelo. Lo anterior ocurrió de manera significativa en las comunidades de Santa Isabel Ixtapan, Nexquipáyac 
y Santa Rosa. Si bien a la fecha no se ha construido un megaproyecto urbano en la región de Texcoco, sí hay venta de tierra ejidal, asentamientos irregulares y un nuevo conflicto social cuyo protagonista fue un gobernador por sus decisiones mal tomadas y su escaso conocimiento de la problemática económica, social y política de la región. Es preciso analizar la dimensión jurídica, política y social para abordar las reformas municipales que son un componente fundamental en la reforma del Estado, pues es necesario avanzar en la adecuación de las constituciones estatales. Es relevante entender el papel que juegan los gobiernos locales; éstos se asocian en mucho en la gestión local con adecuada administración donde puedan enfrentar los problemas y demandas más importantes de la población, atendiendo el mandato de la comunidad. Esto comprende varias dimensiones; las más importantes son la espacio-territorial, la financiera, la social y la ambiental.

El FPDT es una organización de carácter multifacético integrada por diversos actores de la vida social que presenta en su acción múltiples dimensiones. Los campesinos que se dedican a la actividad agrícola en este municipio no son los únicos que protagonizan el movimiento social; se han unido grupos estudiantiles, obreros, organizaciones urbanas, grupos ambientalistas y de derechos humanos, entre otros. Es fundamental entender cómo se articulan en cierto momento este tipo de movimientos diversos frente a un proyecto social; es preciso identificar con una perspectiva sociológica cuáles son las principales demandas de los ciudadanos examinando sus categorías, los actores y las posibles transformaciones del actor-sujeto. El FPDT se identifica a partir de sus mismas demandas; de una misma identidad; de sus principios; de una lucha común; de su condición social, económica y cultural; de sus reivindicaciones y sus características socioculturales; de una lucha por conservar cierto tipo de vida y de organización. Es una crítica a la racionalidad económica prevaleciente donde las reacciones sociales se pueden confrontar con la dinámica de la modernidad, con la globalización. Se tiene la impresión de que estas luchas están latentes, de que se mueven en el ámbito de los nuevos paradigmas relacionados con un nuevo desarrollo, con la seguridad, con el respeto de nuestro entorno, con la democracia, con la libertad. Desde el movimiento del EZLN en Chiapas los nuevos movimientos sociales expresan una tensión, se manifiestan en un descontento generalizado que se ha venido acumulando debido a la difícil situación de la economía y de la seguridad, y a las difi- 
cultades para conseguir un mejor empleo, un equitativo reparto de la riqueza nacional y un cambio en el ejercicio del poder. La protesta masiva, silenciosa, de los distintos actores de la sociedad ha cobrado fuerza.

\section{Bibliografía}

Alcayaga, Cristina (2002), Atenco, el peso del poder y el contrapeso de la resistencia civil, México, Miguel Ángel Porrúa.

Camacho, Manuel (2011), "Escenarios mexiquenses". Disponible en: <www. eluniversal.com.mx/editoriales/52175.html> (28 de marzo de 2011).

Cisneros, Armando (2002), Crítica de los movimientos sociales, debate sobre la modernidad, la democracia y la igualdad social, México, Universidad Autónoma Metropolitana / Miguel Ángel Porrúa.

Comisión Estatal de Población (2009), Zona Metropolitana del Valle de México, México, Comisión Estatal de Población, Estado de México / Sedesol / INEGI / Conapo.

Estados Unidos Mexicanos (2006), Constitución Política de los Estados Unidos Mexicanos, Artículo 27, párrafos segundo, quinto y sexto, México, Miguel Ángel Porrúa.

Díaz, L. Gloria (2009), "Peña a la compra de votos", Proceso, núm. 1 685, 15 de febrero.

Giddens, A., B. Zygmunt, y N. Luhman (2001), Las consecuencias perversas de la modernidad: modernidad, contingencia y riesgos, Buenos Aires, Anthropos.

H. Ayuntamiento de Atenco (2003), Plan Municipal de Desarrollo Urbano, Atenco, Gobierno del Estado de México / H. Ayuntamiento de Atenco.

H. Ayuntamiento de Atenco (2006), Informes de gobierno de 2003-2009 de Atenco, Atenco, H. Ayuntamiento de Atenco.

Instituto Electoral del Estado de México (2011), "Resultados de las elecciones de los años 1996, 2000, 2003, 2006 y 2009”, Numeraria Edomex. Disponible en: <www.ieem.org.mx/procesoselectorales/ayuntamientos> (22 de enero de 2012).

Instituto Mexiquense de Cultura (2003), Monografía de Atenco, Toluca, Gobierno del Estado de México / Instituto de Cultura Mexiquense.

INEGI (1990), XI Censo General de Población y Vivienda, México, Instituto Nacional de Estadística, Geografía e Informática.

INEGI (2000), XII Censo General de Población y Vivienda, México, Instituto Nacional de Estadística, Geografía e Informática.

INEgi (2010a), Censo de Población y Vivienda, México, Instituto Nacional de Estadística y Geografía.

INEGI (2010b), Anuario estadístico del Estado de México, t. 1, México, Instituto Nacional de Estadística y Geografía. 
INEgi (2010), Anuario estadístico del Estado de México, t. 2, México, Instituto Nacional de Estadística y Geografía.

Instituto Nacional para el Federalismo y el Desarrollo Municipal (2002), Ficha básica complementaria del municipio de Atenco, México, Instituto Nacional para el Federalismo y el Desarrollo Municipal.

López, Luis (2009), “Actores, movimientos y conflictos. ¿Es posible la acción colectiva en un contexto de fragmentación sociocultural?, en Sergio Zermeño et al. (coords.), Los movimientos sociales: de lo local a lo global, México, UAM-A / Antropos.

Moreno, Enrique (2008), Un estudio social, urbano y ambiental de los municipios de Texcoco y Atenco. El caso del proyecto del aeropuerto internacional en el Estado de México, Toluca, IAPEM (Premio IAPEM 2006).

Munck, Gerardo (1995), "Algunos problemas conceptuales en el estudio de los movimientos sociales”, Revista Mexicana de Sociología, vol. 57, núm. 3, pp. $17-40$.

Secretaría de Desarrollo Urbano y Vivienda del Estado de México y H. Ayuntamiento de Atenco (1993), Plan de Desarrollo Urbano de Atenco, Toluca, Gobierno del Estado de México.

Tamayo, Sergio (2009), "Participación ciudadana y movimientos sociales", en Sergio Zermeño et al. (coords.), Los movimientos sociales: de lo local a lo global, México, UAM-A / Antropos.

Touraine, Alain (2005), Producción de la sociedad, México, UNAM / IFAL.

\section{Entrevistas en Atenco}

Miguel Ángel Rodríguez, encargado de gobernación del Ayuntamiento Constitucional de Atenco 2009-2012, 26 de agosto de 2011.

Tonatiuh Martínez Cabrera, asistente del secretario particular del presidente municipal de Atenco 2009-2012, 10 de noviembre de 2011.

Igor Álvarez Mora, secretario particular del presidente municipal del Ayuntamiento de Constitucional de Atenco, 11 de marzo de 2012.

\section{Acerca del autor}

Enrique Moreno Sánchez es maestro en Sociología y doctor en Urbanismo por la UNAM. En 2008 obtuvo el primer lugar del Premio IAPEM del Instituto de Administración Pública del Estado de México, en la modalidad de Investigación Teórica. Ha colaborado en distintos libros y publicado más de 20 artículos en revistas especializadas, entre los que destacan: "Texcoco en lo sociourbano y económico. Periodo 20002012”, Quivera, vol. 15, núm. 2, 2013, pp. 63-92; "El aeropuerto y el 
movimiento social de Atenco", Convergencia. Revista de Ciencias Sociales, vol. 17, núm. 52, 2010, pp. 79-95; "Indicadores para el estudio de la sustentabilidad urbana en Chimalhuacán, Estado de México”, Estudios Sociales, vol. 22, núm. 43, 2014, pp. 159-186; y "Análisis de las condiciones económicas y políticas para la superación de la pobreza en el municipio de Texcoco de Mora en el Estado de México", Carta Económica Regional, Universidad de Guadalajara, 2009.

Sus líneas de investigación son: gobierno local, desarrollo sociourbano y movimientos sociales, y gobierno local, región y ambiente.

Actualmente es profesor de tiempo completo del Centro Universitario UAEM Texcoco de la Universidad Autónoma del Estado de México, institución en la que es miembro del cuerpo académico Política y Gobierno. Pertenece al Sistema Nacional de Investigadores, SNI. 